\title{
Spacelab a monument to the past
}

The European spacecraft is neither an outright waste of money nor a potential platform for better things but a reminder that software (in the sense of forethought) is more important than mere hardware.

THE postponement of the first Spacelab launch until either November or next February is both a cruel disappointment for the European Space Agency and a salutary reminder of the dangers in this field, as in others, of putting too many eggs in one basket. Spacelab has been the focus of the space agency's forward planning since 1969, when the United States set out to interest potential partners in the development and operation of the space shut tle system. The chances were never bright that some other government would agree to become a minority shareholder in the shuttle as such. As events have shown, that would have been a blankcheque commitment. More than a decade ago, it seemed safer that Europe should instead shoulder responsibility for a significant piece of hardware that would also make a substantial contribution to general understanding.

That is the origin of Spacelab, a removable vacuum-tight canister fitting in the cargo bay of the shuttle on whose development and construction the European Space Agency has spent more than $\$ 1,000$ million. The first flies in the ointment became apparent more than five years ago, when it became plain that the shuttle itself would be seriously delayed. Earlier this year, it was also apparent that the communications system needed to relay the full range of Spacelab data to the ground would be incomplete. Now the first flight of Spacelab is likely to be put off until next year, with all the financial consequences that will have for the space agency's budget. The agency's officials are doing the best they can to wring some kind of compensation from the shuttle's managers, the National Aeronautics and Space Administration in the United States. The people who have built equipment for the flight, and who must now kick their heels, are unlikely to be much comforted by whatever emerges from that negotiation.

But why blame bad luck? That will be the passably forgivable reaction of those responsible for this project. And it is true that in a different world, one in which ceramic tiles never peel off the shuttle's surface and in which rocket engines never malfunction, that line of defence would be acceptable. In the real world, however, the excuse carries no conviction. The trouble with the Spacelab project is that it has been from the outset hardware-led. The huge canister designed to occupy the shuttle's cargo bay is almost an embarrassment. Making the fullest use of the space available has meant that a miscellaneous collection of experiments, each thoroughly worthwhile in itself, has to be welded into a manageable package - and then equipped (or halfequipped) with a purpose-built communications system. The crew who will be looking after this motley collection of equipment next month or in February will have their work cut out to know what next to do.

\section{Ambition}

The underlying error is that the European Space Agency's ambitions more than a decade ago surpassed what should have been its realistic assessment of its members' needs. Even then, when the decision to embark on Spacelab was taken, Europe was filled with groups from several disciplines clamouring for the opportunity to launch instruments into orbits about the Earth. With the passage of time, the clamour has become louder. But most of the unsatisfied users of orbits about the Earth would prefer that the effort spent in designing and developing an instrument should be requited by a spell of several months, even several years, in orbit - not just the few days that the shuttle will provide at this early stage. Sensibly enough, the European agency is hoping to develop a container that will be roughly half the size of Spacelab (rejoicing in the name EURECA) which would be launched on a commercial basis by the shuttle, and which could be left in orbit for several months before recovery and reuse. That could be a means of satisfying the need that has arisen. The hope now is that the agency's enthusiasm for Spacelab will not have persuaded member governments that the agency is not to be trusted.

Meanwhile, it seems certain that Europe will become the chief source of published information on the behaviour of materials in circumstances in which gravitational forces are only a small fraction - one thousandth or even a ten-thousandth - of those on the surface of the Earth. From the outset, the European agency has made "microgravity" its own. The result is that the first version of Spacelab has been fitted out with a variety of equipment that should throw important light on such things as the form of the interaction between different phases of the same material, or the behaviour of composite materials in circumstances in which the different densities of different components are of no account. Most of the experiments planned for the now postponed launching of the first Spacelab will be valuable contributions to basic understanding. As yet, however, it seems to be agreed among those responsible for these experiments, it is too soon to know whether it will ever be worthwhile to use orbiting stations as miniature factories for the production of superior alloys, or of pharmaceutical products of much greater purity than can be had on the surface of the Earth. The snag, unfortunately, is that by no stretch of the imagination would the member states of the European Space Agency have clubbed together to mount such an investigation if it were an isolated objective. Even the microgravity programme, imaginative and potentially valuable though it is, is in the last resort nothing but a kind of space-filler in almost the literal sense.

\section{Neglect}

The moral in all this should be clear. More than ten years ago, the European Space Agency (or, more strictly, the European Space Research Organization from which it partly sprang) seriously misjudged its future role. Impressed with the need for a project large enough to serve as a focus for a whole range of activities, and anxious also to demonstrate that Europe could play a part in partnership even with organizations such as the US National Aeronautics and Space Administration, the managers of this nascent activity plumped for hardware when software - or even nothing - would have better served the need. For much of the intervening period, they and their successors have been criticized for their neglect of basic science, especially when the development of the Ariane rocket system was eating holes in the collective budget. The danger now is that past errors will be taken as proof of present fallibility - a danger all the greater because the space agency's account of what Spacelab will accomplish when eventually it is launched shows no trace of the self-doubt that would be proper. To be safe, however, what the agency should be saying is that Spacelab is a monument to an earlier period - one in which governments were more prosperous and the technical community less certain (for good reason) what might be done with Earth satellites. 